\title{
Prevalence of hypertension in children after early repair of coarctation of the aorta: a cohort study using casual and 24 hour blood pressure measurement
}

\author{
J J O’Sullivan, G Derrick, R Darnell
}

Heart 2002;88: 163-166

\begin{abstract}
Objective: To study the prevalence of hypertension in a cohort of patients using the current strategy of repair in early childhood.

Patients: The cohort of patients with coarctation of the aorta born between 1983 and 1992 .

Intervention: Casual (mean of three resting readings) and 24 hour blood pressure were measured in 119 children and compared with data from 1034 normal controls. The arch repair and left ventricular parameters were assessed using Doppler echocardiography.

Results: Median ages at first intervention and at blood pressure measurement were 0.2 years (interquartile range $0.04-2.0$ ) and 12.0 years (9.0-14.5), respectively. Doppler velocity in the descending aorta was significantly associated with blood pressure $(r=0.28, p=0.002$ for casual systolic blood pressure (SBP); $r=0.26, p=0.005$ for mean 24 hour SBP). Patients were classified as having "no" $(n=70)$ or "mild" $(n=49)$ arch obstruction. Casual SBP was $>95$ th centile in 28\% (34 of 119) overall and in $21 \%$ (15 of 70) of the no arch obstruction group. Mean 24 hour SBP was $>95$ th centile in $30 \%$ (36 of 119 ) overall and in 19\% (13 of 70) of the no obstruction group. The sensitivity and specificity of casual SBP in detecting increased 24 hour SBP were $66 \%$ and $88 \%$, respectively. Conclusions: This unique study of a large cohort of patients treated for coarctation in early childhood showed that a disappointingly high prevalence of hypertension is already apparent in children aged 7-16 years in the absence of significant arch obstruction, whether assessed by 24 hour or by casual
\end{abstract}

See end of article for authors' affiliations

Correspondence to: Dr J O'Sullivan, Freeman Hospital, Newcastle upon Tyne NE7 7DN, UK; i.j.o'sullivan@ncl.ac.uk Accepted 29 April 2002

................... blood pressure measurement.

$\mathrm{C}$ oarctation of the aorta is associated with an increased risk of hypertension in adult life. ${ }^{1}$ Upper body hypertension would be expected if the repair was suboptimal ${ }^{2}$ or growth of the transverse arch or the repaired segment was poor. ${ }^{3}$ There is good evidence, however, that even in the presence of a good repair increased blood pressure is common in adults. ${ }^{4-9}$

One of the factors that has been shown to contribute to the subsequent risk of hypertension is the age at the time of the original repair. ${ }^{169}{ }^{10}$ This is one of the reasons why coarctation is now usually definitively treated at presentation, which is usually in early childhood. Even though the operative mortality associated with early surgery has been reported, ${ }^{11}{ }^{12}$ there are as yet no data on the medium term blood pressure status of the cohort of patients operated on in the 1980s and early 1990s. The main purpose of this study was to investigate this cohort of patients and determine the prevalence of hypertension in those children who are now aged 7-16 years. The study used casual and 24 hour blood pressure measurements and used centiles from a large body of normal children of similar age to define those with abnormal 24 hour blood pressure.

\section{METHODS}

Children $(<16$ years) with a diagnosis of coarctation of the aorta were identified from the departmental database. This was checked by accessing the hospital database and by going through all the ward admission books and operating theatre books. Details of the type and date of operation were obtained from the surgeons' reports. Children were examined in the hospital outpatient department. The right arm was used unless the right subclavian artery was known to be aberrant.

A trained nurse measured blood pressure manually with the patient in the sitting position after at least five minutes' rest using a mercury sphygmomanometer. The arm was measured to ensure proper cuff size and a Doppler probe was used to locate the brachial artery in the antecubital fossa. The mean of three readings was used as the casual blood pressure measurement. Twenty four hour blood pressure was measured using the Takeda TM-2421 (A \& D, Saitama, Japan) and its reliability in children has been reported in studies from this department. ${ }^{13}$ The nurse was aware of the interventions the patient had as it may influence the positioning of the arm cuff. A modified right arm cuff was available and accuracy of the device was checked using a t-piece connector, which allowed simultaneous readings by the monitor and the mercury sphyngomanometer. ${ }^{13}$ The monitor was worn for 24 hours and children were encouraged to go back to school but to avoid physical education classes or participation in formal sporting activities. The device measured blood pressure every 30 minutes during the day and every hour between 2200 and 0700 .

A detailed echocardiographic assessment was carried out at the same visit. Arch dimensions were measured at the peak of the $\mathrm{R}$ wave, and the transverse arch (beyond the innominate artery), the narrowest point at the site of the coarctation repair, and the descending aorta at the diaphragm were measured. A continuous wave Doppler measurement was also made in the descending aorta. Left ventricular end diastolic and systolic dimensions were measured. A phonocardiogram was placed over the aortic area and moved to obtain a clear signal of the second heart sound. The mitral inflow Doppler was recorded using a narrow width pulse volume sample placed at the tip of the mitral leaflets from an apical four chamber view. ${ }^{14}$ On the same screen the phonocardiogram signal was displayed and the isovolumic relaxation time was measured. For each of these the mean of three measurements was used. 
Table 1 Details of age (mean), sex, and blood pressure of the 119 children studied

\begin{tabular}{llllll}
\hline & $\begin{array}{l}\text { Subclavian } \\
\text { flap repair }\end{array}$ & $\begin{array}{l}\text { End to end } \\
\text { anastomosis }\end{array}$ & Balloon & Patch & Other \\
\hline Age at operation (years) & 0.75 & 1.68 & 7.24 & 5.4 & 0.5 \\
Age at blood pressure reading (years) & 10.8 & 10.4 & 12.8 & 12.1 & 12.5 \\
$24 \mathrm{~h} \mathrm{SBP}(\mathrm{mm} \mathrm{Hg})$ & 127.9 & 115.6 & 122.4 & 122 & 120 \\
Daytime SBP $(\mathrm{mm} \mathrm{Hg})$ & 136.5 & 122.1 & 127.8 & 128.0 & 125.0 \\
Night time SBP (mm Hg) & 108.3 & 100.4 & 109.9 & 109.0 & 106.0 \\
Casual SBP (mm Hg) & 119.5 & 110.2 & 116.5 & 124.1 & 115.8 \\
Male (\%) & $12(70)$ & $48(72)$ & $7(47)$ & $5(55)$ & $9(82)$ \\
Total & 17 & 67 & 15 & 9 & 11 \\
\hline SBP, systolic blood pressure. & & & & & \\
\hline
\end{tabular}

All of the children studied were considered to have had a satisfactory coarctation repair and none were being actively considered for reintervention. However, they could be divided into a group with no residual obstruction and a group with mild residual coarctation. No residual obstruction was defined as an arch velocity of $<2.5 \mathrm{~m} / \mathrm{s}$ without a diastolic tail and a widely patent arch on cross sectional echocardiography. Daytime blood pressure was defined as that between 0700 and 2200. Normal 24 hour blood pressure data were obtained from the large study using similar monitoring equipment from our department. ${ }^{15}$ Normal casual blood pressure data were obtained from published data. ${ }^{16}$ The statistical package $\mathrm{R}^{17}$ was used for all statistical testing including $\mathrm{z}$ tests and $t$ tests for testing the significance of Pearson's correlation coefficient.

\section{RESULTS}

This study was confined to children who were $<16$ years and $>6$ years old at the time of the study (1999-2000). There were 166 children born between 1983 and 1992 (inclusive) on the database with a diagnosis of coarctation of the aorta. Of the total cohort 20 had died. Of the 146 long term survivors, nine could not be contacted and 11 did not wish to participate. This was mainly because of anticipated difficulties with returning the monitor on the following day or parental concerns with regard to their children wearing the blood pressure monitor for 24 hours. The remaining 126 children were studied. In seven cases the data from the 24 hour monitor were of poor quality and were not used. The data from 119 children are presented.

The median age of the children at the time of blood pressure and Doppler measurements was 11.1 years (interquartile range (IQR) 8-14 years). Other cardiac lesions were present in $38 \%$ (46 of 119) of the participants; these were ventricular septal defect in $22 \%$ (27 of 119), aortic stenosis in 6\% (7 of 119 ), mitral valve disease in 5\% (6 of 119), and transposition of the great arteries in 5\% (6 of 119). The median age at operation for the total group was 0.22 years (IQR 0.04-2.02 years) and the mean follow up was 9.5 years (IQR 7.1-12.8 years). The "other" operations referred to in table 1 were mainly a combination of subclavian flap and end to end anastomosis or extended end to end anastomosis. There were significant age differences between the groups, with the children who had undergone primary balloon dilatation or patch repairs being significantly older than those who had undergone subclavian flap or end to end anastomosis.

Overall, there was a significant correlation between systolic blood pressure (SBP) and residual obstruction as measured by Doppler velocity in the descending aorta. The correlation with Doppler velocity in the descending aorta was $0.26(\mathrm{p}=0.005)$ for 24 hour mean SBP and $0.28(p=0.002)$ for the casual blood pressure measurement. Even though some children had mild residual coarctation, no child in the study was being considered for reintervention and the highest descending aorta Doppler velocity obtained was $3.5 \mathrm{~m} / \mathrm{s}$. Of the 119 children, 70 were classified as having no residual obstruction, based on
Table 2 Prevalence of hypertension as determined by casual and 24 hour blood pressure measurement in the total group and in the group with no evidence of residual arch obstruction, and the sensitivity and specificity of increased casual systolic blood pressure in detecting increased 24 hour SBP

\begin{tabular}{lllll}
\multicolumn{5}{c}{ in detecting increased 24 hour SBP } \\
\hline & $\begin{array}{c}\text { Normal } \\
24 \mathrm{~h} \text { SBP }\end{array}$ & $\begin{array}{c}\text { High } \\
24 \mathrm{~h} \text { SBP }\end{array}$ & Sensitivity & Specificity \\
\hline Total group ( $\mathrm{n}=1$ 19) & & & & \\
$\quad$ Normal casual SBP & 73 & 12 & & \\
High casual SBP & 10 & 24 & $66 \%$ & $88 \%$ \\
$\quad$ Total & 83 & 36 & & \\
$\begin{array}{l}\text { No residual arch } \\
\text { obstruction }\end{array}$ & & & & \\
$\quad$ Normal casual SBP & 49 & 6 & & \\
High casual SBP & 8 & 7 & $54 \%$ & \\
Total & 57 & 13 & & \\
\hline & & & & \\
\end{tabular}

resting echocardiographic assessment and a widely patent arch on cross sectional echocardiography. A greater proportion of the patients with subclavian flap were in the no obstruction group but this was not significant $(p=0.13)$. There was no significant difference in the age at intervention between the non-obstructed and mildly obstructed groups (1.86 $v 1.87$ years).

\section{Casual blood pressure}

Casual blood pressure in the coarctation patients was compared with the normal resting values derived from six European studies. ${ }^{15}$ Of the 119 children who had coarctation repair, $34(28.5 \%)$ had a mean resting SBP reading $>95$ th centile of the normal population (table 2 ). When the analysis was confined to those operated on in infancy the proportion who had significantly increased casual blood pressure did not change significantly (20 of 77; 26\%). When the analysis was confined to those with no residual obstruction (table 2), a similar proportion, 15 of $70(21.5 \%)$, were $>95$ th centile for the mean resting casual SBP measurement.

\section{Twenty four hour blood pressure}

The 24 hour mean SBP of each child was compared with the normal 24 hour blood pressure data obtained using the same blood pressure device from a large group of 1034 normal schoolchildren aged from 6-16 years. ${ }^{15}$ Overall, the coarctation group had significantly higher mean 24 hour, daytime, and night time SBP (all p < 0.001). The differences remained statistically different (all $\mathrm{p}<0.001$ ) when those with mild arch obstruction were removed.

Thirty six children (36 of $119 ; 30 \%$ ) had a mean 24 hour SBP $>95$ th centile of the age specific normal population (table 2). When the analysis was confined to those operated on in infancy the proportion who had significantly increased 24 hour blood pressure did not change significantly (21 of 77; 
Table 3 Comparison between recent studies on blood pressure in patients with coarctation of the aorta and the present study

\begin{tabular}{|c|c|c|c|c|c|c|}
\hline $\begin{array}{l}\text { Author and } \\
\text { reference }\end{array}$ & $\begin{array}{l}\text { Number of } \\
\text { participants }\end{array}$ & $\begin{array}{l}\text { Mean (SD) age at } \\
\text { operation (years) }\end{array}$ & $\begin{array}{l}\text { Mean follow up } \\
\text { (years) }\end{array}$ & $\begin{array}{l}\text { Hypertension } \\
\text { determined by } \\
\text { casual SBP (\%) }\end{array}$ & Controls & $\begin{array}{l}\text { Hypertensive } \\
24 \text { h SBP (\%) }\end{array}$ \\
\hline Giordano $^{20}$ & 38 & Children & $2.6(3)$ & 16 & Lit & 34 \\
\hline Leandro ${ }^{21}$ & 20 & $5.5(4.3)$ & $9.2(3.1)$ & Ex & 20 & NA \\
\hline Eroglu 22 & 18 & $5.1(4.8)$ & $2.5(1.9)$ & Ex & 18 & NA \\
\hline Parrish ${ }^{23}$ & 11 & $6.0(1.0)$ & 10.1 (1.0) & NA & 15 & 45 \\
\hline Hauser $^{24}$ & 55 & $2.8(2.2)$ & 7.9 & 45 & Lit & $19 *$ \\
\hline Johnson ${ }^{25}$ & 21 & $5.5(4.6)$ & $9.4(4.9)$ & 27 & Lit & $29 *$ \\
\hline Present study & 119 & $0.2(0.04-2.0) \dagger$ & $9.5(7.1-12.8) \dagger$ & 30 & 1034 & 19 \\
\hline
\end{tabular}

Controls shows the number of controls used to assess the prevalence of hypertension using 24 hour recordings.

Ex, patients with hypertension were excluded; Lit, controls from the literature; NA, not available.

*If mean 24 hour blood pressure was not given, the prevalence of daytime hypertension was used; †median and interquartile range.

$27 \%)$. When those with mild arch obstruction were excluded (table 2$), 13$ of $70(18.5 \%)$ had mean 24 hour readings $>95$ th centile of the normal population.

\section{Can casual blood pressure measurement identify} children with high 24 hour blood pressure?

Table 2 presents the sensitivity and specificity of an increased casual blood pressure measurement. An increased casual blood pressure has good specificity $(88 \%)$ in detecting an increased 24 hour blood pressure but has a relatively poor sensitivity $(66 \%)$. It can be seen that the sensitivity and specificity of casual blood pressure measurement in detecting increased 24 hour pressure do not change significantly when the children with no residual obstruction are analysed separately.

\section{Blood pressure and left ventricular measurements}

The mean 24 hour blood pressure was correlated with certain Doppler echocardiographic measures of left ventricular function. There was no significant correlation between the mitral inflow velocities (E:A ratio) and mean 24 hour blood pressure $(r=0.026, \mathrm{p}=0.78, \mathrm{n}=117)$. The correlation between isovolumic relaxation time and 24 hour blood pressure was also not significant $(r=-0.091, \mathrm{p}=0.36$, $\mathrm{n}=103)$. There was a significant correlation between the interventricular septal thickness and 24 hour blood pressure $(r=0.315, \mathrm{p}=0.001, \mathrm{n}=104)$.

\section{DISCUSSION}

The reported high prevalence of hypertension following successful coarctation repair may be due in large part to the relatively old age at operation in most of the reported series. The limited data available on repair of coarctation in early childhood from surgical series before $1980^{1}{ }^{118}$ suggest a good blood pressure outcome with the current strategy of coarctation repair at presentation, which is commonly in infancy.

Cohen and colleagues ${ }^{1}$ reported from a long term follow up of 646 patients that the small subgroup ( $5 \%$ of the total) operated on in infancy had a low rate of late hypertension (2 of 31; $7 \%$ ) when measured at a mean age of 34 years. Hypertension was defined as a casual SBP measurement of $>150 \mathrm{~mm} \mathrm{Hg}$ or diastolic pressure $>90 \mathrm{~mm} \mathrm{Hg}$. Koller and associates ${ }^{9}$ studied 362 patients operated on between 1961 and 1980 and found that of the 61 patients who were $<2$ years old at operation (17\% of the series), $12(20 \%)$ were hypertensive. However, removal of the eight patients in this group with residual gradients of $>40 \mathrm{~mm} \mathrm{Hg}$ decreased the prevalence of hypertension ( $>140 / 90 \mathrm{~mm} \mathrm{Hg}$ ) to $7.5 \%$ (4 of 53). There are limited short term follow up data available on patients who were operated on in early childhood in the 1980s and early 1990s. Pfammatter and colleagues ${ }^{19}$ studied a group of selected infants who underwent coarctation repair and found that $24 \%$ (11 of 46) of children had supine blood pressure "slightly above the 90th centile for age" when measured a mean of 49 months from repair in infancy. The relatively short follow up and the young age at blood pressure assessment makes the interpretation of these findings difficult.

The feasibility of 24 hour blood pressure measurement in children offered the potential of more reliable blood pressure assessment in this age group, but the diagnosis of hypertension using this technology has been hampered by the lack of reliable 24 hour normal data. The studies that have been carried out using this technology (table 3 ) found a significantly higher mean 24 hour blood pressure in coarctation patients than in controls. ${ }^{20-25}$ Some of these studies have used control data from the literature to define hypertension using the 24 hour blood pressure results and the prevalence of hypertension varies in these studies from 19-45\%. However, these studies are of selected patients and cannot be used as a reliable measure of the prevalence of hypertension in this population.

The availability of a large volume of normal 24 hour blood pressure data in our department ${ }^{15}$ allowed us to use this method to study a cohort of children who were now aged 7-15 years and who had treatment of coarctation in early childhood. The children were being studied an average of 9.5 years following treatment of coarctation of the aorta. When blood pressure was assessed as a resting or casual measurement the prevalence of systolic hypertension (mean reading $>95$ th centile) was $28 \%$ ( 34 of 119). Using the 24 hour mean the prevalence of systolic hypertension was 30\% (36 of 119 ). If those with mild arch obstruction were excluded, the prevalence of hypertension using the casual and 24 hour measurements was $21 \%$ and $19 \%$, respectively. As outlined above there are no similar studies in the literature for comparison, but for completeness table 3 summarises data from studies of blood pressure in selected coarctation patients.

There is evidence in the adult literature that 24 hour blood pressure is a better predictor of end organ damage and therefore provides a better measure of blood pressure than casual readings. ${ }^{26}$ This has not been conclusively proved in children but there are studies that have found a significant association between 24 hour blood pressure and left ventricular dimensions. ${ }^{21}{ }^{24}$ One further issue addressed in our study was the sensitivity of an increased casual blood pressure measurement in screening for increased 24 hour blood pressure. Increased casual SBP has good specificity (over 85\%) and is therefore clinically useful in this regard. Casual blood pressure measurement is not very sensitive $(66 \%)$ and cannot be relied on as a research tool to measure the prevalence of increased 24 hour blood pressure in the coarctation population.

The correlation between ventricular septal thickness and mean 24 hour blood pressure shown by us and other authors $^{21}$ may support the use of antihypertension treatment in these patients. However, the inability to find abnormal diastolic function and the lack of outcome data make it difficult to recommend lifelong treatment of increased blood pressure in these children. Twenty four hour blood pressure has 
been shown to track better than casual blood pressure in adolescence, ${ }^{27}$ but longer term data are needed before we can confidently predict adult hypertension from childhood readings.

To our knowledge this is the first study of the prevalence of hypertension in children with coarctation of the aorta operated on in the 1980s and 1990s. Our data show that a high prevalence of abnormal 24 hour blood pressure is already apparent in later childhood after successful treatment of the coarctation in early life. The study did not investigate the reasons for hypertension after a good arch repair but the observation that arterial reactivity is impaired in adults who have had a neonatal repair ${ }^{28}$ is in keeping with our findings.

\section{ACKNOWLEDGEMENTS}

The study was supported by a grant from the National Heart Research Fund and by the Anne Coleman Trust. We are indebted to Sister Amanda Griffiths for her enthusiasm and meticulous data collection.

\section{Authors' affiliations}

J J O'Sullivan, G Derrick, Department of Paediatric Cardiology, Freeman Hospital, Newcastle upon Tyne, UK

R Darnell, Department of Statistics, University of Newcastle upon Tyne, Newcastle upon Tyne, UK

\section{REFERENCES}

1 Cohen M, Fuster V, Steele PM, et al. Coarctation of the aorta: long term follow up and prediction of outcome after surgical correction. Am Heart J 1989;80:840-5.

2 Freed MD, Rocchini A, Rosenthal A, et al. Exercise induced hypertension after surgical repair of coarctation of the aorta. Am J Cardiol 1979:43:253-8

3 Ong CM, Canter CE, Gutierrez FR, et al. Increased stiffness and persistent narrowing of the aorta after successful repair of coarctation of the aorta: Relationship to left ventricular mass and blood pressure at rest and with exercise Am Heart J 1992:123:1594-9.

4 Maron BJ, Humphries JO, Rowe RD, et al. Prognosis of surgically corrected coarctation of the aorta: a 20 year postopeerative appraisal. Circulation 1973;47:119-26.

5 Prasad M, Moodie D, Blechman G, et al. Long term follow-up of aortic coarctation in infants, children and adults. Cardiol Young 1993:3:20-6.

6 Presbitero $\mathbf{P}$, Demarie D, Villani $M$, et al. Long-term results (15-30 years) of surgical repair of aortic coarctation. $\mathrm{Br}$ Heart $\mathrm{J}$ 1987;57:462-7.

7 Patel R, Singh SP, Abrams L, et al. Coarctation of the aorta with special reference to infants. Br Heart J 1977:39: 1246-53.

8 Shinebourne EA, Tam AS, Elseed AM, et al. Coarctation of the aorta in infancy and childhood. Br Heart J 1976;38:375-80.
9 Koller M Rothlin M, Senning A. Coarctation of the aorta: review of 362 operated patients. Long term follow-up and assessment of prognostic variables. Eur Heart J 1987;8:670-9.

10 Bergdahl L, Bjork VO, Jonasson R. Surgical correction of coarctation of aorta: influence of age on late results. J Thorac Cardiovasc Surg 1983;85:532-6.

11 Quaegebeur JM, Jonas RA, Weinberg AD, et al. Outcomes in seriously ill neonates with coarctation of the aorta. J Thorac Cardiovasc Surg 1994; 108:841-54.

12 Rubay JE, Sluysmans T, Alexandrescu V, et al. Surgical repair of coarctation of the aorta in infants under one year of age. J Cardiovasc Surg 1992:33:216-21.

13 O'Sullivan JJ, Derrick G, Griggs PE, et al. Validation of the Takeda 2421 blood pressure monitor in children. J Med Eng Technol 1998;22:101-5.

14 Bu'Lock FA, Mott MG, Martin RP. Left ventricular diastolic function in children measured by Doppler echocardiography: normal values and relation with growth. Br Heart J 1995;73:334-9.

15 O'Sullivan JJ, Derrick G, Griggs P, et al. Ambulatory blood pressure in schoolchildren. Arch Dis Child 1999;80:529-32.

16 De Man SA, Andre J, Bachmann H, et al. Blood pressure in childhood: pooled findings of six European studies. J Hypertens 1991:9:109-14.

17 Ihaka R, Gentleman R. R: a language for data analysis and graphics. J Comput Graph Stat 1996;5:299-3 14.

18 Nanton MA, Olley PM. Residual hypertension after coarctectomy in children. Am J Cardiol 1976;37:769-72.

19 Pfammatter JP, Ziemer G, Kaulitz R, et al. Isolated aortic coarctation in neonates and infants: results of resection and end to end anastomosis. Ann Thoac Surg 1996;62:778-83.

20 Giordano U, Matteucci MC, Calzolari A, et al. Ambulatory blood pressure monitoring in children with aortic coarctation and kidney transplantation. J Paediatr 2000;136:520-3

21 Leandro J, Smallhorn J, Benson L, et al. Ambulatory blood pressure monitoring and left ventricular mass and function after successful surgical repair of coarctation of the aorta. J Am Coll Cardiol 1992;20:197-204.

22 Eroglu AG, Oztung EF. Ambulatory blood pressure monitoring after successful repair of coarctation of the aorta at mid-term follow-up. Jpn Heart J 2000:41:49-58.

23 Parrish MD, Torres E, Peshock R, et al. Ambulatory blood pressure in patients with occult recurrent coarctation of the aorta. Pediatr Cardiol 1995; 16:166-71

24 Hauser M, Keuhn A, Wilson N. Abnormal responses for blood pressure in children and adults with surgically corrected aortic coarctation. Cardiol Young 2000;10:353-7.

25 Johnson D, Perrault $H$, Vobecky J, et al. Influence of postoperative period and surgical procedure on ambulatory blood pressure: determination of hypertension load after successful surgical repair of coarctation of the aorta. Eur Heart J 1998;19:638-46.

26 Parati G Pomidossi G Albini F, et al. Relationship of 24-hour blood pressure mean and variability to severity of target-organ damage in hypertension. J Hypertens 1987,5:93-8.

27 O'Sullivan JJ, Derrick G, Foxall RJ. Tracking of 24-hour and casual blood pressure: a one year follow up study in adolescents. J Hypertens 2000, 18:1193-6.

28 Gardner HM, Celermajer D, Sorenson KE, et al. Arterial reactivity is significantly impaired in normotensive young adults after successful repair of aortic coarctation in childhood. Circulation 1994;89:1745-50.

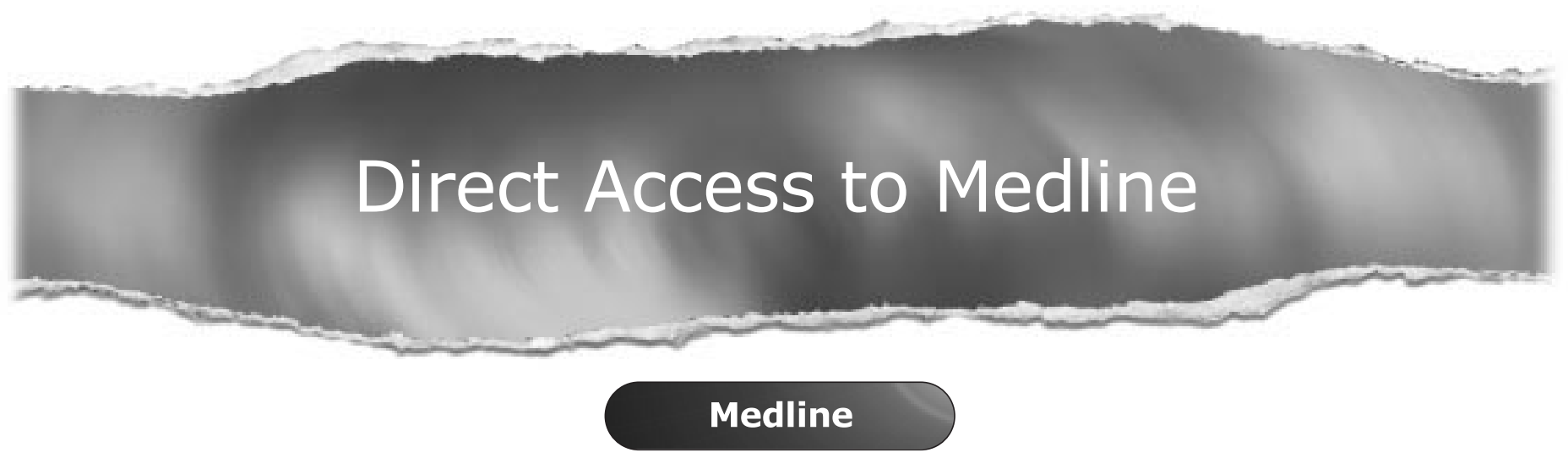

Link to Medline from the homepage and get straight into the National Library of Medicine's premier bibliographic database. Medline allows you to search across 9 million records of bibliographic citations and author abstracts from approximately 3,900 current biomedical journals. 